\title{
Assessment of thyroid dysfunction, dyslipidemia and oxidative stress in hypertensive end stage chronic renal disease patients in a teaching hospital in Western Uttar Pradesh
}

\author{
Poonam Kachhawa', Vivek Sinha ${ }^{2}$ \\ ${ }^{1,2}$ Associate Professor, Department of Biochemistry, Saraswathi Institute of Medical Sciences, Hapur, Uttar Pradesh, India
}

Background: CKD is a serious health problem in worldwide. In developing nation, CKD has severe implication on health and economic output. The rapid increase of common risk factors such as hypertension (HTN), obesity and type 2 diabetes will result in greater and more burdens to developing country. There are many complications associated with CKD including thyroid dysfunction, dyslipidemia, hypertension and cardiovascular disease (CVD). It is generally seen that patients suffering from CKD are at high risk of cardiovascular disease. Aims and Objectives: The purpose of the study was to evaluate the diagnostic screening of thyroid dysfunction, dyslipidemia and oxidative stress in hypertensive end stage chronic renal disease patients. Materials and Methods: Thyroid status, Lipid profile, serum Urea, serum Creatinine, serum Uric acid, serum electrolyte, Catalase,Malondialdehyde (MDA) and Superoxide dismutase (SOD) were assayed in 160 subjects in which 80 patients of CKD were having hypertension and 80 healthy controls. Results: In our study, we found statistical significantly increased level of $(p<0.001)$ of malondialdehyde (MDA) and significantly decreased level $(p<0.001)$ of Catalase and Superoxide dismutase (SOD). There was found significantly increased level $(p<0.001)$ of TSH in CKD associated with hypertension patients. We also found deranged lipid profile and renal functions in CKD associated with hypertension patients as compared to controls. Conclusion: In the present study, we arrived at conclusion that dyslipidemia and thyroid dysfunction is very common in CKD patients. Our study revealed that there was significant association between thyroid dysfunction and CKD progression and dyslipidemia. The antioxidant status is assessed through changes in antioxidant enzymatic activity in patients of CKD with hypertensive and data provide evidence of blood pressure modulation by measurable oxidative stress-related parameters.

Key words: Hypertension (HTN); Chronic Kidney Disease (CKD); Reactive Oxygen Species (ROS); Oxidative Stress; Glomerular Filtration Rate (GFR)

\section{INTRODUCTION}

Chronic kidney disease is accompanied by persistent kidney damage, reduction in the glomerular filtration rate and the presence of albuminuria. ${ }^{1}$ Chronic kidney disease is a serious health problem in worldwide. In developing nation, CKD has severe implication on healthand economic output. The rapid increase of common riskfactors such as hypertension (HTN), obesity and type 2 diabetes (T2D) will resultin greater and more burdens to developing country are noteasy to handle. It is a established fact that CKD is associated with number of complications, including dyslipidaemia, hypertension, cardiovascular disease (CVD) and thyroid dysfunction. ${ }^{2}$ It is very often 
seen that chronic renal failure patients may have various thyroid function complications. ${ }^{3}$ We know that our kidney normally plays an important role in the thyroid hormones metabolism, degradation and excretion. There are research evidencesshowed that dyslipidemia may contribute to progression of renal disease. ${ }^{4}$ Dysfunction of thyroid gland can affect the thyroid hormones (T3 and T4) production which is associated with various physiological functions within the body. Thyroid hormone levels have significant affect during the course of progression of CKD. It is commonly seen that disorders of renal function have co-relation with specific thyroid hormone levels. This study is done to establish relations between kidney disease and thyroid function. The Information obtained from this study will help to improve clinical knowledge and facilitate clinicians to give better management and care to their patients who have dysfunctions of kidney or thyroid gland. Many studies have established that Total cholesterol and LDL cholesterol values are important markers of cardiovascular mortality. ${ }^{5}$ In patients with CKD, hypertriglyceridemia is a common lipid abnormalities. ${ }^{6,7}$ There is decrease lipoprotein lipase and hepatic triglyceride lipase activity in CKD patients. As such, there is hindrance in the uptake of triglyceride rich, apolipoprotein B containing lipoproteins by the liver and in peripheral tissue, resulting in atherogenic lipoproteins. ${ }^{2}$ Accelerated hypertension is an major risk factor for developing $\mathrm{CKD}$, is reported to occur in 80 to $90 \% \mathrm{CKD}$ patients (stages 3-5). ${ }^{8}$ Hypertension causes more rapid progression of CKD. ${ }^{9}$ Many research guidelines have proved that by lowering blood pressure (BP), the progression of kidney disease and cardiovascular morbidity and mortality ${ }^{10}$ can be avoided. The oxidative stress generated in CKD patients causes increase in ROS (reactive oxygen species). Resulting various redox sensitive cell signaling molecules activated and cytotoxic materials produced. This is followed by cellular dysfunction and damage. This finally results in microvascular complications. ${ }^{11}$ It is seen that thyroid dysfunction and dyslipidaemia in patients of CKD increases the cardiovascular morbidity and mortality risk. ${ }^{12,13}$ Hence, early diagnosis of thyroid dysfunctions and dyslipidaemia in CKD patients may be highly helpful to slow the CKD progression. This could be done by regular screening of the patients. This study was therefore aimed to evaluate the effect of thyroid dysfunction, dyslipidemia and degree of oxidative stress in Hypertensive CKD patients.

\section{MATERIALS AND METHODS}

\section{Study design}

This is a Randomized, Prospective and Comparative case control study in Saraswathi Medical college and Hospital, Hapur (Uttar Pradesh).

\section{Study area}

The study was conducted in Hapur District, Uttar Pradesh, India.

\section{Study period}

The study was completed from August 2017 to Nov 2018.

\section{Study setting}

The study was carried out in the Biochemistry Department, Saraswathi Medical College and Hospital, Hapur (UP).

\section{Study population}

This study population comprised total 160 subjects in which 80 healthy control (Group I), 80 CKD with hypertension (Group II). All the people with age group 20 years and above living in the study area were eligible to participate in the study.

\section{SELECTION OF CASES}

\section{Inclusion criteria}

1. Adult patients (more than or 18 years aged) reporting first time/regularly associated with SIMS hospital for management of Hypertension issue are selected.

2. Only mild to moderate grade hypertensive patients were taken

3. Patients consenting for the study.

\section{Exclusion criteria}

Cases with the following findings will be excluded:

1. Patients with known thyroid disorders

2. Hypertensive patients suffering from any other medical problems and on medications affecting thyroid function, lipid profile and blood pressure were excluded from the study

3. Patients with history of drug abuse or history of psychiatric disorder

4. Other factors causing hypertension

5. Cancer or suspicion of malignancy

6. Pregnancy

7. Angina

8. Hypertensive emergency.

\section{Study population}

Sample size was calculated by the probability sampling formula below:

$$
\mathrm{N}=\mathrm{Zpq} / \mathrm{d}
$$

Where, $\mathrm{n}=$ sample size, $\mathrm{z}=$ statistical certainty chosen, $\mathrm{p}=$ proportion of hypothyroid individuals with hypertension, $\mathrm{q}=1-\mathrm{p}$ and $\mathrm{d}=$ precision desired. 


\section{Ethical approval}

This current study was approved by the Ethical Committee of the Institute and all guidelines of the ethical committee were followed.The aim and objectives of the study were explained to the ethical committee.

\section{Informed consent}

A written signed informed Consent letter was obtained from each patient before starting the procedure. The involvement of the subject was voluntary.

A structured questionnaire regarding the age, sex, duration of Hypertension, BMI were measured. Personal history was taken from each patient e.g. smoking habit, BP (Blood pressure), family history of renal disease, hypertension and diabetes etc. Total $5 \mathrm{ml}$ of blood sample was taken from the antecubital vein after overnight fasting. The collected blood samples werecentrifuge for $15 \mathrm{~min}$. at $3000 \mathrm{rpm}$ at room temperature. The separated serums were stored in refrigerator at $4^{\circ} \mathrm{C}$ for biochemical investigations. Samples were analyzed for serum urea, creatinine, uric acid, lipid profile, TSH (thyroid stimulating hormone), free T3 (triiodothyronine) and free T4 (thyroxine). Serum Urea, creatinine, uric acid, and lipid profile were measured by enzymatic method on auto analyzer. Serum total cholesterol, HDL-cholesterol, and TG were estimated using commercially available kit of auto analyzer. All biochemical investigation was done by fully automated analyzer (CPC chem100). Serum TSH, free T3, and free T4 were estimated by fluorescent immunoassay on minividas. Thyroid dysfunction was considered if patients thyroid hormones profilesderanged; TSH (normal range $=0.25-5 \mathrm{mIU} / \mathrm{L}$ ), free T3 (normal range $=2.30-5.0 \mathrm{ng} / \mathrm{mL}$ ) and free T4 (normal range $=10.6-19.4 \mathrm{pmol} / \mathrm{L}$ ). Subclinical hyperthyroidism was considered as free T3 and free T4 within reference range and TSH $<0.25 \mathrm{mIU} / \mathrm{L}$. Subclinical hypothyroidism was defined if free $\mathrm{T} 3$ and free T4 within reference range and TSH $>5 \mathrm{mIU} / \mathrm{L}$. Overt hypothyroidism was considered as free T3 $<2.30 \mathrm{ng} / \mathrm{mL}$ and free T4 $<10.6 \mathrm{pmol} / \mathrm{L}$ and TSH $>5 \mathrm{mIU} / \mathrm{L}$. SOD (Serum super oxide dismutase) activity was measured by the Marklund and Marklund (1988) method. ${ }^{14}$ Serum catalase activity was estimated by the Aebi (1984) method. ${ }^{15}$ Plasma MDA (Malondialdehyde) was estimated by Jeanet et al. ${ }^{16}$

\section{STATISTICAL ANALYSIS}

Biochemical Statistical analyses were done by SPSS 21 software. Results were put in the tables asmean and standard deviation and were significance analyzed by using unpaired Student's t-test. The level of significant was set as $\mathrm{P}<0.05$ : Significant and $\mathrm{P}>0.05$ : Nonsignificant.

\section{RESULTS}

Table 1 showed sex, age, BMI, blood pressure (DBP, SBP) inhypertensive CKD patients and controls. The mean age of the $80 \mathrm{CKD}$ with HTN patients was 51.9 with $56.25 \%$ of the patients being male. The mean age of the 80 healthy controls was 49.7 with $52.5 \%$ of the controls being male. There was no significant difference inresults of sex, age and BMI between the two case and control groups. Blood pressure (SBP \& DBP) was significantly increased in the cases compare to control subjects.

Table 2 showed biochemical characteristics of hypertensive CKD patients.Serum creatinine levels, serum urea levels, and serum uric acid levels were significantly increased $(\mathrm{P}<0.001)$ in case group as compared to control group. In case group, we found T. cholesterol, LDL-cholesterol, Triglycerides, and VLDL-cholesterol levels were significantly increase compare than control, whereas HDL-cholesterol level was significantly decreased $(\mathrm{P}<0.001)$ in cases as compare to control group. The data shows the high risk of CVD in patients of CKD.

\begin{tabular}{|c|c|c|c|}
\hline Parameters & $\begin{array}{l}\text { Control } \\
(\mathrm{N}=80)\end{array}$ & $\begin{array}{l}\text { CKD with HTN } \\
(\mathrm{N}=80)\end{array}$ & $\mathrm{p}$-value \\
\hline Age & $49.7 \pm 5.8$ & $51.9 \pm 7.8$ & NS \\
\hline Male:Female & $42: 38$ & $45: 35$ & NS \\
\hline BMI $\left(\mathrm{kg} / \mathrm{m}^{2}\right)$ & $22 \pm 1.7$ & $23.5 \pm 2.7$ & NS \\
\hline $\mathrm{SBP}(\mathrm{mmHg})$ & $119.2 \pm 5.2$ & $137.2 \pm 6.9$ & $<0.001$ \\
\hline $\mathrm{DBP}(\mathrm{mmHg})$ & $79.6 \pm 4.4$ & $91.7 \pm 4.8$ & $<0.001$ \\
\hline
\end{tabular}

HTN: Hypertension, CKD: Chronic kidney disease, SBP: Systolic blood pressure, DBP: Diastolic blood pressure and BMI: Body mass index

\begin{tabular}{lccc}
\multicolumn{4}{l}{ Table 2: Biochemical features of hypertensive } \\
$\begin{array}{l}\text { CKD patients and controls (Mean } \pm \text { SD) } \\
\text { Parameters }\end{array}$ & $\begin{array}{l}\text { Control } \\
(\mathrm{N}=80)\end{array}$ & $\begin{array}{c}\text { CKD with HTN } \\
(\mathbf{N}=80)\end{array}$ & p-value \\
\hline $\begin{array}{l}\text { Serum urea } \\
\text { (mg/dL) }\end{array}$ & $25.3 \pm 5.7$ & $91.6 \pm 27.3$ & $<0.001$ \\
$\begin{array}{l}\text { Serum creatinine } \\
\text { (mg/dL) }\end{array}$ & $0.8 \pm 0.3$ & $5.3 \pm 1.7$ & $<0.001$ \\
$\begin{array}{l}\text { Serumuric acid } \\
\text { (mg/dL) }\end{array}$ & $4.5 \pm 1.2$ & $6.6 \pm 1.8$ & $<0.001$ \\
$\begin{array}{l}\text { Total cholesterol } \\
\text { (mg/dl) }\end{array}$ & $165.6 \pm 16.13$ & $229.9 \pm 45.2$ & $<0.001$ \\
$\begin{array}{l}\text { HDL-cholesterol } \\
\text { (mg/dl) }\end{array}$ & $46.7 \pm 5.93$ & $40.8 \pm 5.37$ & $<0.001$ \\
$\begin{array}{l}\text { LDL-cholesterol } \\
\text { (mg/dl) }\end{array}$ & $118.7 \pm 27.6$ & $158.9 \pm 35.5$ & $<0.001$ \\
$\begin{array}{l}\text { Triglycerides } \\
\text { (mg/dl) }\end{array}$ & $125.8 \pm 38.3$ & $276.3 \pm 54.3$ & $<0.001$ \\
$\begin{array}{l}\text { VLDL-cholesterol } \\
\text { (mg/dl) }\end{array}$ & $22.9 \pm 8.5$ & $50.5 \pm 24.6$ & $<0.001$ \\
\hline
\end{tabular}

LDL: Low density lipoprotein, VLDL: Very low density lipoprotein and HDL: High density lipoprotein 
Table 3 showed Thyroid function of hypertensive CKD patients and controls.Significantly increase TSH level $(\mathrm{P}<0.001)$ and decreasing free T3 and free T4 levels were found (decrease were not significant) across CKD with HTN, which suggest that level of TSH increases with the progression of renal damages (which is indicated by a decrease in GFR).

Table 4 showed oxidative stress markers and eGFRof hypertensive CKD patients. eGFR were significantly lower $(\mathrm{P}<0.001)$ in hypertensive $\mathrm{CKD}$ patients as compared to control group. In case group antioxidant level (SOD and Catalase activity) showed significantly decreased $(\mathrm{P}<0.001)$ and MDA was found significantly high $(\mathrm{P}<0.001)$ in comparison to control subjects.

\section{DISCUSSION}

Our present study was of the view that thyroid dysfunction, dyslipidemia and oxidative stress are common disorder in Indian CKD patients. In our study we found that thyroid dysfunctions werepresent in 38.6\% CKD patients, in which the most common was subclinical hypothyroidism type around $27.2 \%$ patients, followed by $8.1 \%$ patients were overt hypothyroidism and subclinical hyperthyroidism patients were only $3.3 \%$. Our result was consistent with the finding of several previous studies. ${ }^{17} \mathrm{~A}$ small study was conducted in CKD patients dependent on hemodialysis in western Uttar Pradesh. This study showed the combined prevalence $(26.6 \%$ patients) of clinical and subclinical hypothyroidism. ${ }^{18} \mathrm{~A}$ previous Study of Lo et al concluded

\begin{tabular}{lccc}
\multicolumn{4}{l}{ Table 3:Thyroid function of hypertensive CKD } \\
patients and controls (Mean \pm SD) \\
\hline Parameters & $\begin{array}{c}\text { Control } \\
(\mathbf{N}=\mathbf{8 0})\end{array}$ & $\begin{array}{c}\text { CKD with HTN } \\
(\mathbf{N}=\mathbf{8 0})\end{array}$ & p-value \\
& $2.94 \pm 0.81$ & $3.21 \pm 0.21$ & $\mathrm{NS}$ \\
\hline Free T3 $(\mathrm{ng} / \mathrm{mL})$ & $15.6 \pm 3.2$ & $16.48 \pm 4.61$ & $\mathrm{NS}$ \\
Free T4 $(\mathrm{pmol} / \mathrm{L})$ & $3.2 \pm 0.34$ & $7.39 \pm 2.61$ & $<0.001$ \\
\hline TSH (mIU/L) &
\end{tabular}

TSH: Thyroid stimulating hormone and $\mathrm{T}_{3}$ : Triiodothy-ronine, $\mathrm{T}_{4}$ : Thyroxine

\section{Table 4: Oxidative stress markers and eGFRof} hypertensive CKD patients and controls

\begin{tabular}{lccc}
\hline Parameters & $\begin{array}{c}\text { Control } \\
(\mathbf{N}=80)\end{array}$ & $\begin{array}{c}\text { CKD with HTN } \\
(\mathbf{N}=80)\end{array}$ & p-value \\
\hline $\begin{array}{l}\text { SOD activity } \\
\text { (Units/gmHb) }\end{array}$ & $6.1 \pm 1.1$ & $3.1 \pm 0.6$ & $<0.001$ \\
$\begin{array}{l}\text { Catalase activity } \\
\text { (Units/gmHb) }\end{array}$ & $7.2 \pm 0.9$ & $4.1 \pm 0.5$ & $<0.001$ \\
MDA $(\mathrm{nmol} / \mathrm{mL})$ & $1.5 \pm 0.2$ & $5.1 \pm 0.8$ & $<0.001$ \\
$\begin{array}{l}\text { eGFR measured } \\
\text { by MDRD equation } \\
\left.\text { (mL/min/1.73 m } \text { m }^{2}\right)\end{array}$ & $95.8 \pm 26.3$ & $44.4 \pm 8.9$ & $<0.001$ \\
\hline eGFR: Estimated glomerular filtration rate & & \\
\hline
\end{tabular}

that the prevalence of hypothyroidism increased with lower GFR level, they found GFR greater than or equal to 90 in $5.4 \%$ subjects, GFR $60-89$ in $10.9 \%$ subjects, GFR $45-59$ in $20.4 \%$ subjects, GFR $30-44$ in $23.0 \%$ subjects, and GFR $<30$ in $23.1 \%$ subjects $(p<0.001$ for trend). ${ }^{12}$ An Indian study showed prevalence of subclinical hypothyroidism was $24.8 \%$ in ESRD (end stage renal failure) patients. ${ }^{19,20}$ Our result was of the view that increase in the level of lipid profile (total cholesterol, VLDL-C, TG, and LDL-C) was possible explanation for deranged lipid metabolism to accelerate the progression of CVD in CKD patients through various paths. Firstly, the tubular epithelial cells, reabsorb phospholipids, cholesterol and fatty acids contained in the filtered proteins can stimulate tubulointerstitial inflammation and then formation of foam cell, and causes tissue injury. ${ }^{21}$ Secondly, lipoproteins accumulation in glomerular mesangium can promote production of matrix and glomerulosclerosis. ${ }^{22}$ For CKD patients, some of the studies have shown a good association between risk for cardiovascular events and total cholesterol values, ${ }^{23}$ whereas other studies did not show any significant correlation. $^{24}$ In our CKD patients have reduced plasma HDL-C levels, many other study consistency with us ${ }^{1,25}$ possible explanation of decrease level of HDL-C is decrease level of apolipoproteins AI and AII, abnormal activity of lecithin: increased activity of Cholesterol, cholesteryl ester transfer protein, which help the transfer of cholesterol esters from HDL-C to TG-rich lipoproteins, and so there is reduction in the serum concentrations of HDL-C. ${ }^{26}$ During the course of our study, we observed that there is a strong relationship between some oxidative stress-related parameters and blood pressure. Whenever ROS production is elevated, there is reduce in the endothelium dependent vasodilatation of the vascular smooth muscle cells of hypertensive patients. ${ }^{27}$ It is also seen that whenever there is blood pressure increases, there is ROS increase, thus increasing the mechanism of ROSmediated hypertension. In this present study, there was significantly decrease the superoxide dismutase activity in the case group, indicating that either the scavenging system has been consumed during CKD or is suppressed. The major reason for decreased superoxide dismutase activity is the glycosylation of superoxide dismutase which has been shown to lead to enzyme inactivation. ${ }^{16}$ Compromised functions of antioxidant result in the well-known cascade of hypoxic ischemic injury, inflammation, apoptosis and finally cell death. ${ }^{28}$ The significant decrease activity of catalase in present study agreement with various previous studies found a lower activity of antioxidant enzyme ${ }^{16}$ and a negative correlation between activity of Catalase and both day time DBP and SBP in hypertensive CKD patients. ${ }^{29}$ Elevated level of catalase and possible explanation for this is that increase in catalase activity in these groups could be a compensatory mechanism of the body to prevent 
damages of tissue by the raised free radicals as it was not supported by a corresponding increase of other antioxidant enzymes activities. ${ }^{30}$ Possible explanation production of ROS in hypertension elevated lipid peroxidation in cellular membrane as well as enhancing the protein carbonyl derivatives and producing higher level of MDA in the hypertensive CKD patients which is a suggestive feature of oxidative stress in hypertension. Our these results are also consistent with the previous study. ${ }^{16}$

\section{CONCLUSIONS}

The present study is of the view that thyroid dysfunction and dyslipidemia is very frequent in CKD patients. It establishes that significant association between thyroid dysfunction and CKD progression and dyslipidemia. Our study comes to the conclusion that CKD patients with dyslipidemia have strong predisposition for developing CVD, so that early treatment for dyslipidemia in CKD patients may reduce the chance of developing CVD later. Thus primary investigation shows that status of antioxidant is controlled through changes in antioxidant enzymatic activity in CKD with hypertensive patients and data provide suggestion of controlling blood pressure by oxidative stress-related parameters. Patients of CKD are affected by multiple associated conditions like dyslipidemia, hypertension and diabetes which are all related with oxidative stress. The presence of chronic kidney disease appears to further increase the oxidative stress independently from the underlying conditions. Hemodialysis also plays important role in contributing to the oxidative stress. Enhancing evidence indicates that oxidative stress is a probable independent CVD risk factor in CKD. CVD is a significant cause of morbidity and mortality in patients of impaired kidney functions. Additionally, identification of functional and/or biochemical biomarkers could be used in clinical practice to monitor oxidative imbalance CKD.

\section{ACKNOWLEDGEMENT}

Department of Biochemistry, Saraswathi Institute of Medical Sciences.

\section{REFERENCES}

1. Malyszko J, Malyszko J, Wolczynski $S$ and Mysliwiec $M$ Adiponectin, leptin and thyroid hormones in patients with chronic renal failure and on renal replacement therapy: are they related? Nephrol Dial Transplant 2016; 21(1):145-152.

2. Prospective Studies Collaboration1, Lewington S, Whitlock G, Clarke R, Sherliker P, Emberson J, et al. Blood cholesterol and vascular mortality by age, sex, and blood pressure: A meta-analysis of individual data from 61 prospective studies with 55,000 vascular deaths. Lancet 2015; 370:1829-1839.
3. Attman PO, Samuelsson. Dyslipidaemia of kidney disease. Curr Opin Lipidol 2013; 20:293-299.

4. Kwan BC, Kronenberg F, Beddhu S and Cheung AK. Lipoprotein metabolism and lipid management in chronic kidney disease. J Am Soc Nephrol 2013; 18:1246-1261.

5. Kaysen GA. Lipid and lipoprotein metabolism in chronic kidney disease. J Ren Nutr 2012; 19:03-07.

6. Thomas R, Kanso A and Sedor JR. Chronic kidney disease and its complications. Prim Care 2009; 35(2):329-344.

7. Rao Mv, Qiu Y, Wang C and Bakris G. Hypertension and CKD: Kidney Early Evaluation Program (Keep) and National Health and Nutrition Examination Survey (NHANES), 1999-2004. Am J Kidney Dis 2008; 51(Suppl 2):S30-S37.

8. Botdorf J, Chaudhary $\mathrm{K}$ and Whaley-Connell A. Hypertension In Cardiovascular and Kidney Disease. Cardiorenal Med 2008; 1:183-192.

9. Chobanian AV, Bakris GI, Black HR, Cushman WC, Green LA, Izzo JL, et al. The Seventh Report of the Joint National Committee on Prevention, Detection, Evaluation, and Treatment of High Blood Pressure: The Jnc 7 Report. JAMA 2007; 289:2560-2572.

10. Evans JL, Goldfine ID, Maddux BA and Grodsky GM. Oxidative stress and stress-activated signalling pathways: A unifying hypothesis of type 2 diabetes. Endocr Rev 2006; 23:599-622.

11. Lo JC, Chertow GM, Go AS and Hsu CY. Increased prevalence of subclinical and clinical hypothyroidism in persons with chronic kidney disease. Kidney Int 2005; 67(3):1047-1052.

12. Collaboration PS, Lewington S, Whitlock G, Clarke R, Sherlinker P, Emberson J, et al. Blood cholesterol and vascular mortality by age, sex and blood pressure a meta-analysis of individual data from 61 prospective studies with 55,000 vascular deaths. Lancet 2005; 370(9602):1829-1839.

13. Marklund $S$. and Marklund G. Involvement of the superoxide anion radical in the autoxidation of pyrogallol and a convenient assay for superoxide dismutase. Eur J Biochem 2005; 47:469-474.

14. Aebi H. Catalase in Vitro. Methods Enzymol 24; 105:121-126. International journal of medical sciences and public health 2004 ; 5(12):1-7.

15. Jean Cd, Maryse $\mathrm{T}$ and Marie JF. Plasma malondialdehyde levels during Myocardial Infarction. Clinica Chimica Acta 1999; 129:319-322.

16. Sinha V, Kumar A and Kachhawa P. Thyroid dysfunction and dyslipidaemias in patients with chronic kidney diseases. International journal of medical sciences and public health 1998; 5(12):1-7.

17. Paudel K. Prevalence and clinical characteristics of hypothyroidism in a population undergoing maintenance haemodialysis. J Clin Diagn Res 1998; 8(4):MC01-MC04.

18. Kachhawa K, Varma M and Kachhawa P. Study of dyslipidaemias and cystatin $C$ levels as a predictive marker of CKD in type 2 diabetes mellitus patients at a teaching hospital in central India. J Inte Neph Andro 1997:3(1):24-28.

19. Shantha GPS, Kumar AA, Bhise V, Khanna R, Sivagnanam K and Subramanian KK. Prevalence of subclinical hypothyroidism in patients with end-stage renal disease and the role of serum albumin: a cross-sectional study from South India. Cardiorenal Med 1997; 1(4):255-260.

20. Magil AB. Interstitial foam cells and oxidized lipoprotein in human glomerular disease. Mod Pathol 1997;12: 33-40.

21. Li W, Wang G, Lu X, Jiang $Y, X u L$ and Zhao X. Lycopene ameliorates renal function in rats with streptozotocin-induced diabetes. Int J Clin Exp Pathol 1996; 7:5008-5015.

22. Koch M, Kutkuhn B, Trenkwalder E, Bach D, Grabensee B, Dieplinger $\mathrm{H}$, et al. Apolipoprotein B, fibrinogen, HDL cholesterol, 
and apolipoprotein (a) phenotypes predict coronary artery disease in hemodialysis patients. J Am Soc Nephrol 1997; 8:1889-1898.

23. Shlipak MG, Fried LF, Cushman M, Manolio TA, Peterson D, Stehman-Breen C, et al. Cardiovascular mortality risk in chronic kidney disease: Comparison of traditional and novel risk factors. JAMA 1996; 293:1737-1745.

24. Kachhawa K, Varma M and Kachhawa P. Study of dyslipidemia and antioxidant status in chronic kidney diseases patients at a hospital in South East Asia. J Health Res Rev 1996-6; 3(1):28-30.

25. Kimura H, Miyazaki R, Imura T, Masunaga S, Suzuki S, Gejyo $F$, et al. Hepatic lipase mutation may reduce vascular disease prevalence in hemodialysis patients with high CETP levels. Kidney Int 1994;64:1829-1837.

26. Lassègue $B$ and Griendling $K$. Reactive oxygen species in hypertension. An Update Am J Hypertens 1994; 17:852-860.

27. Simic DV, Mimic-Oka J, Pljesa-Ercegovac M, et al: Byproducts of oxidative protein damage and antioxidant enzyme activities in plasma of patients with different degrees of essential hypertension. J Hum Hypertens 1994; 20:149-155.

28. Kumawat M, Sharma TK, Singh I, et al. Oxidative stress in patients with hypertension. Journal of Advance Researches In Biological Sciences 2013; 5 (4) 352-356.

29. Hodis HN, Mack WJ, Azen SP, Alaupovic P, Pogoda JM, Blankenhorn DH, et al. Circulation 1994;90:42-49.

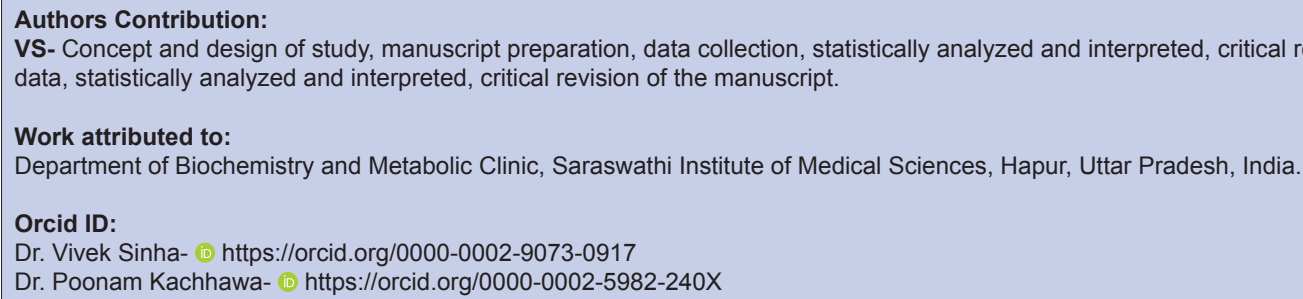

